\title{
The Study on the Independent and Available Experimental Teaching Mode of the Functional Experiment of Medical Science Based on Achievement
}

\author{
Xin Li, Xiaodong Cui, Hongying Lu, Dexiu Wang, Wentao Li and Chengwen Jin* \\ The laboratory of the functional experiment of medical science, School of Basic Medicine Sciences, Weifang Medical \\ University, Weifang, Shandong, 261053, PR China \\ *Corresponding author. Email: jinchw@126.com
}

\begin{abstract}
Medical education is an important cornerstone of health development. However, there are still some problems in China's medical education, such as personnel training structure need to be optimized, training quality need to be improved, innovation and practice ability need to be improved. The medical function is an experimental subject. Because of the current situation of the teaching platform in the laboratory, the author discusses the experimental teaching reform based on the results-oriented. After completing the regular teaching and research tasks, open the laboratory in spare time. Organize students to enter the laboratory in the form of the team. Use the knowledge and literature query to design the experimental project and implementation route and complete the testing process. The practice has proved that this method can stimulate students' potential, help to mobilize students' learning enthusiasm and creativity and cultivate students' ability to think and solve problems independently, and promote the improvement of medical students' practice and innovation ability.
\end{abstract}

Keywords: Achievement-oriented, Medical Science, Functional science, Experimental teaching.

\section{INTRODUCTION}

Practical teaching is a very important link in the teaching of medical colleges and universities. It plays an irreplaceable role in cultivating students' practical ability and creative ability [1]. It is a "bridge" between basic medicine and clinical practice.

According to the syllabus requirements, there is a certain proportion of experimental courses and theoretical courses in the class hour arrangement. In the limited class hours, students can only complete the specified practical projects and exploration and could not completely test the students' Mastery of this new subject. How to improve the students' practical ability and creative ability in the functional experiment is always the core issue discussed by medical higher education workers. Open experimental teaching in the new form is the breakthrough point of modern personnel training mode innovation, which is particularly important for medical and health personnel training in medical colleges [2].
In this paper, Weifang Medical University functional experiments nearly ten years of open experimental teaching achievements and problems in the teaching process to do in-depth discussion.

\section{CONSTRUCTION OF OPEN EXPERIMENTAL CONDITIONS}

Under normal circumstances, the laboratory should undertake the daily experimental teaching tasks and part of scientific research tasks. Limited by time, space, and resources, the laboratory can only use the weekdays and spare time to open to students regularly to ensure the satisfaction of time and space and provide the necessary space-time conditions for students to enter the laboratory.

At present, the laboratory has 6 virtual laboratories and 12 operation laboratories. The cloud resource library of virtual experiment online courses is opened, covering 6 available courses. Students can access the system at any time to consult learning materials and experiment with related knowledge by using the network. 


\section{ESTABLISHMENT OF OPEN EXPERIMENTAL PROJECT}

For more than ten years, students have been insisting on opening the laboratory independently. They have designed the experimental projects they are interested in and completed the practical projects independently in the laboratory on the premise that the experimental conditions are basically met. Since functional experiments are all living animal experiments except virtual experiments, there are many difficulties for students to enter the laboratory to complete an experiment independently. Objectively, it requires students to take a group as a unit, with more or less personnel. It is appropriate to form an experimental group of 3-5 people and independently select a group leader to be responsible for the specific operation of the testing project.

\subsection{Requirements for Experimental Project Approval}

An open experiment requires students to submit project applications 2 weeks in advance. Students' experimental projects should have a detailed experimental design scheme and technical route, including main research content, direction, purpose, innovation, feasibility analysis, experimental methods, and essential technology, expected experimental results, etc. The laboratory organizes teachers to demonstrate the feasibility of the experimental project and finally obtains the project approval.

\subsection{Experimental Project Training}

After the laboratory approved the project, the experimental project was established immediately. According to the content of the experiment, the laboratory teachers provide the corresponding experimental instruments, experimental drugs, experimental animals, and the corresponding experimental space, and the students can enter the laboratory to prepare for the experiment. During this period, the laboratory will arrange teachers on duty to guide students to use the instrument correctly, explain the precautions of the experiment, deal with emergencies in the experiment, and pay attention to safety matters to prevent accidents from endangering students' personal safety.

\section{OBJECTIVES OF OPEN EXPERIMENT}

\subsection{Develop Collaborative Teamwork}

The completion of independent experiments and the team spirit of cooperation among students is particularly important. Because the students form teams freely and complete the designed experimental projects in a team way, some of the students in the group have made outstanding achievements in some fields of the subject, while others have also made outstanding achievements in other aspects. The common hobbies and interests, the common environment, is conducive to students to give full play to their advantages, the knowledge learned flexible application to practice, through mutual learning and exchange, broaden thinking, common improvement, in the harvest of knowledge at the same time also enhance the friendship between students, students in the experimental process should learn to cooperate, cooperation, until a tacit understanding, To cultivate team spirit is also the key to the success of the experiment [3].

\subsection{Evaluate Students' Ability of Knowledge Integration and Application}

The functional experiment involves many theoretical subjects. Experimental design requires students to have a certain ability to use knowledge and solve some practical problems in theory and technology encountered in the actual experiment process at any time. At the same time, in the experiment process, students need to discuss in their own groups where the experimental results conflict with the theoretical results to give full play to the main role of students. Teachers can provide students with heuristic guidance to help them solve the problems that can not be solved finally, which can reserve the space for students to think independently and give full play to their personal initiative and creative potential. For complex problems, the laboratory teachers will guide students to consult relevant literature, provide theoretical guidance for students in the experiment, and break the traditional model that teachers put forward problems and solve problems according to textbooks in the experimental class.

In addition, to attract students to actively participate in open experiments, the laboratory regularly holds academic lectures related to experimental design to stimulate students' enthusiasm to participate in open investigations so that students can learn in practice and grow in practice. In the actual practical operation, the students' desire for exploration and knowledge is satisfied. This is conducive to teaching students in accordance with their aptitude, reasonable allocation of limited teaching resources, and conducive to broadening students' horizons, improving students' interest in learning, and enhancing students' comprehensive quality.

\subsection{Cultivate Students' Awareness of Scientific and Technological Innovation}

Students are required to make experimental records, keep complete original empirical data, and submit 
practical reports in the form of scientific research papers after completing the collection and statistical analysis of experimental data.

Based on the development of students, the open experiment focuses on cultivating students' thinking mode, innovative consciousness, and practical ability of scientific problems. In completing the experiment, students no longer accept knowledge passively but acquire knowledge by playing their potential.

Guide students to pay attention to the connection between theory and practice and the relationship between basic and clinical. In practice, instructors are no longer the main body of the traditional mode of teaching courses but the participants and en-lighteners of students' learning. They help students transform the essence of theoretical knowledge into practical ability and promote students' ability to use inside.

\subsection{Feedback of Open Experiment Results}

The principle of students' experiment design is that the process is more important than the result. First of all, respect the personal initiative and creativity of students.
Even if the results in the experiment are contrary to the design, teachers should not rashly deny students. Still, help students find out the causes of problems and the possible factors of such results, and patiently help students analyze the problems. For successful experiments, experimental reports should be submitted in the form of scientific research papers, and the reference materials involved should be marked. The practical report in the form of the scientific research paper is complex for the students to write for the first time in both format and content, and there will be many problems. The teachers in the laboratory will give the students correct guidance in time, from the collection of experimental data to the processing of data, and strive to improve and solve all kinds of problems encountered in the experiment.

The survey found that students' satisfaction with the effect of functional independent open experiments reached $95.7 \%$. The main reason for dissatisfaction was that some drugs could not be purchased and did not fully meet the needs of the investigation. The satisfaction survey results are shown in Table 1.

Table 1. Satisfaction survey of "functional independent open experiment"

\begin{tabular}{|c|c|c|}
\hline Investigation content & options & The percentage \\
\hline Satisfaction degree of & Quite satisfied & $14.2 \%$ \\
\hline functional independent open & Very satisfied & $81.5 \%$ \\
\hline experiment & Discontent & $4.3 \%$ \\
\hline
\end{tabular}

At present, due to the limitation of laboratory space, time, personnel, and funds, the independent experimental project can not meet the learning needs of students, but students have widely recognized the experimental effect.
The students fully affirmed the necessity of the independent open experimental project and played a due role in promoting the Mastery of basic knowledge, the improvement of basic skills, the cultivation of unity and cooperation spirit, and innovation ability. We have followed up the survey results in the past five years as follows as shown in Table 2:

Table 2. The independent open experimental project and played the due role

\begin{tabular}{|c|c|c|c|c|c|c|}
\hline Contents & 2016 & 2017 & 2018 & 2019 & & 2020 \\
\hline innovation ability & $87.30 \%$ & $85.50 \%$ & $93 \%$ & $94.70 \%$ & $\%$ & 97.20 \\
\hline $\begin{array}{l}\text { operational } \\
\text { capacity }\end{array}$ & $85.20 \%$ & $89.70 \%$ & $91.60 \%$ & $92.00 \%$ & $\%$ & 93.50 \\
\hline $\begin{array}{l}\text { knowledge } \\
\text { extension }\end{array}$ & $85.90 \%$ & $86.30 \%$ & $87.80 \%$ & $88.60 \%$ & $\%$ & 89.70 \\
\hline team spirit & $87.40 \%$ & $86.90 \%$ & $88.10 \%$ & $89.30 \%$ & & $91.70 \%$ \\
\hline necessity & $93.70 \%$ & $95.60 \%$ & $97.80 \%$ & $98.20 \%$ & & $99.10 \%$ \\
\hline
\end{tabular}




\section{THE SIGNIFICANCE OF OPEN EXPERIMENTAL TEACHING}

\subsection{Impact of Open Experiment on Students}

Open experimental teaching is a new teaching mode formed under the concept of quality education and innovative education [4]. It provides students with a fully open and free experimental research environment. Under the guidance of teachers, students learn relevant knowledge step by step and purposefully design practical content and organize the implementation. In this kind of teaching practice, students no longer simply and passively verify the theoretical knowledge in the classroom, but fully mobilize students' enthusiasm and creativity in learning, give full play to their imagination and creativity, make the experimental teaching from simple demonstration and verification into design and innovation, cultivate students' innovative consciousness and practical ability, which is conducive to the display of students' personality and specialty, it can give full play to its creative potential.

\subsection{Impact on Teachers}

It promotes the construction of an experimental teaching team and is conducive to the comprehensive development of teachers' knowledge. Open experimental teaching needs a new type of teacher with a comprehensive and dynamic knowledge structure and modern experimental technology [5]. Medical and functional experiments span multiple disciplines, and the practical programs designed by students may also involve a variety of experimental techniques. This requires the experimental instructor to constantly strengthen the expansion and update of their knowledge and skills to achieve rich expertise and comprehensive technology. They should not only master the theoretical knowledge and experimental technology of their specialty, master the most cutting-edge scientific research information and technology trends of their specialty, but also understand the theoretical knowledge and technology of other related specialties, and understand the latest progress of medical research frontier in associated fields[6]. Therefore, open experimental teaching is also a challenge to teachers, which is conducive to the growth of teachers and interdisciplinary penetration.

\subsection{Change of Experimental Teaching Mode}

The open laboratory teaching is different from the traditional experimental course. In the process of guiding students to experiment, we should pay attention to avoid conflict with traditional teaching. In the specific process of implementation, teachers should not intervene too much. When students encounter problems in the experiment that need to be solved by teachers, the problems encountered by students are not the traditional teaching model but the outline. They should pay attention to guide and inspire students, use their own hands and brains, give full play to the advantages of the group, find solutions to problems through mutual discussion, and gradually complete the Mastery of knowledge.

\section{CONCLUSIONS}

In conclusion, in the form of the team, students independently complete the experimental tasks according to their practical design scheme and experimental route under the limited guidance of teachers. This kind of experimental teaching method based on achievement orientation has powerfully mobilized students' learning enthusiasm and creativity. It is helpful to cultivate students' ability to think and solve problems independently. Meanwhile, it plays a significant role in promoting the practical innovation ability of medical students.

\section{CONFLICT OF INTEREST STATEMENT}

All authors of this article declare that there is no conflict of interest.

\section{ACKNOWLEDGMENTS}

This work was supported by the Education and Teaching Reform and Research Project of Weifang Medical University (grants 2019ZD004 and 2019YB015), The Ministry of Education IndustryUniversity Cooperation Collaborative Education Project (grants 202002086007 and 201902243014).

\section{REFERENCES}

[1] Vogel, D. and S. Harendza, Basic practical skills teaching and learning in undergraduate medical education - a review on methodological evidence. GMS J Med Educ, 2016. 33(4): p. Doc64.

[2] Zhang, Z., et al., Barriers to obtaining reliable results from evaluations of teaching quality in undergraduate medical education. BMC Med Educ, 2020. 20(1): p. 333.

[3] Wang Q, et al., Exploration and practice of opening experimental teaching platform of medical functional science. Chinese Journal of medical education, 2014, 34(03): p.446-448. (In Chinese)

[4] Bakhshialiabad, H., et al., Improving students' learning environment by DREEM: an educational experiment in an Iranian medical sciences university (2011-2016). BMC Med Educ, 2019. 19(1): p. 397. 
[5] Gartmeier, M., et al., Teacher questions and student responses in case-based learning: outcomes of a video study in medical education. BMC Med Educ, 2019. 19(1): p. 455.

[6] Maggio, L.A., et al., Scoping reviews in medical education: A scoping review. Med Educ, 2021. 55(6): p. 689-700. 